\title{
Comparative Analysis of Three Low Voltage Fault Ride Through Techniques for Wind Energy Conversion Systems
}

\author{
James Tait \\ Dept. of Electronic and Electrical \\ Engineering \\ University of Strathclyde \\ Glasgow, United Kingdom \\ james.g.tait@strath.ac.uk
}

\author{
Khaled Ahmed \\ Dept. of Electronic and Electrical \\ Engineering \\ University of Strathclyde \\ Glasgow, United Kingdom \\ khaled.ahmed@strath.ac.uk
}

\author{
Grain Adam \\ Dept. of Electronic and Electrical \\ Engineering \\ University of Strathclyde \\ Glasgow, United Kingdom \\ grain.ased@strath.ac.uk
}

\begin{abstract}
This paper compares the performances of three different Low Voltage Fault Ride- Through (LVFRT) techniques for Wind Energy Conversion Systems (WECS). The comparison aims to identify the most effective technique for alleviation of adverse impacts of AC faults on WECS electrical and mechanical parts, which include DC voltage rise and generator over-speed. The comparison is based on a critical qualitative review of existing literature on the selected LVFRT techniques, which are further supported by quantitative substantiation using simulations. The major findings of this comparative study are highlighted, with emphasis on metrics, which account for practical implementation, hardware, cost, and complexity issues. They are important to assess the overall effectiveness of the techniques evaluated. Although practical and commercial limitations exist, the initial findings suggest that an energy storage solution would be suitable for the enhancement of LVFRT for WECS in future power networks, and if the stored energy is utilised correctly, offer further attractive benefits.
\end{abstract}

Keywords-Low Voltage Fault Ride Through, Wind Energy Conversion Systems, SMES, Voltage Source Converters

\section{INTRODUCTION}

Global carbon emission targets and socio-economic pressures have seen the rise in renewable energy sources connected to the network. One of the key technologies employed to reduce the carbon emissions related to electricity generation is Wind Energy Conversions Systems (WECS). In 1997, there was approximately $7 \mathrm{GW}$ of installed wind capacity globally, in comparison to $650 \mathrm{GW}$ in 2019 [1]. It is clear that WECS will continue to form an intrinsic part of the power systems in the progress to achieve 2050 carbon emission targets. The way WECS integrates into the system has caused fundamental changes, particularly network behaviour during fault conditions and risks to system security, from lowering short circuit and inertia levels [2]. These are attributed to the asynchronous coupling to the network [3]. As WECS continue to displace large conventional fossil fuel generators, grid codes have evolved to ensure certain operating practices and philosophies are in place to help mitigate system stability issues during fault conditions [3], [5].

WECS are required by Low Voltage Ride Through (LVFRT) requirements in grid codes, applying to transmission and distribution networks to remain connected and transiently stable during network faults for defined periods of time and levels of voltage, commonly for $140 \mathrm{~ms}$ at a voltage level of $0-0.1 \mathrm{pu}$ [6]. Additionally, WECS are permitted to deliver reactive power to the network, during fault and post-fault, to provide the required fault current, to ensure operation of protection and aid in voltage restoration to minimise risk of voltage collapse [5]. During a network fault, the real power delivery from WECS is proportional to the network voltage [7] and all power must be restored to the network within a specified post-fault duration to aid in recovery [8]. WECS employing Permanent Magnet Synchronous Generators (PMSG), equipped with fully rated Voltage Source Converters (VSC), are considered to have inherently improved LVFRT capability over technologies facilitating Induction Generators (IG) and Doubly Fed Induction Generators (DFIG) [9].

As PMSG are fully decoupled from the network, they do not inherently respond to $\mathrm{AC}$ faults or provide the reactive current of the equivalent synchronously coupled generator [7], and network voltage sags create a power imbalance between the generator converter and the network [7]. This imbalance causes a sharp rise in the VSC's DC link voltage due to capacitor overcharging [10]. This effect can cause shutdowns and high levels of stress to the switching devices. In addition to the voltage rises, conventional VSC systems require a strong grid reference voltage to track and deliver power to the network (grid-following converters). When the grid voltage is depressed, the control system is left in an uncontrolled state, and during post-fault recovery, can deliver voltage and power oscillations to the network [11]. For these reasons, techniques to enhance and comply with LVFRT requirements are implemented into WECS systems and focus on providing reactive power to the network and maintaining DC link voltages within limits, which in turn alleviates stress to the mechanical systems.

There are several proposals in literature of ways to mitigate the negative effects to the converter during network faults and comply with grid codes. These can be grouped into three categories, namely real power containment, reactive power compensation and Energy Storage Systems (ESS). Techniques which facilitate reactive compensation have not been included in this paper.

Real power containment techniques aim to limit the power flow into the DC link from the generator side converter during a fault while keeping the DC link within operating range and 
allowing the control system to deliver reactive power into the fault. Blade pitch controllers have been proposed for reducing the rotor speed, thus power flow into the DC link. The dynamics of the system prevent adequate containment of power during faults but may provide coordinated support for prolonged faults or conditions operating in larger time frames [7]. As a means of addressing these limitations, techniques such as switch blocking at the generator side converter will rapidly stop the power flow into the DC link, yet sudden deloading of PMSG will cause rotor acceleration and induce mechanical stress with little grid support [12]. Energy dissipation is a common method, which allows power flow into the DC link during a fault, and dumps the excess energy that cannot be transferred to maintain the DC link within narrow and acceptable limits [7], [13], [14]. This technique meets grid code requirements and alleviates electrical and mechanical stresses; however, it suffers from overheating faults and energy wasting and requires additional hardware. In an effort to address stated shortcomings, [15] proposes coordinated operation between grid and generator side converters in a manner that limits power flow into the DC link proportionally to DC link voltage.

In order not to waste the unutilised energy during LVFRT, ESS is proposed as an attractive solution for power smoothing in order to improve output power quality and provide postfault support in weak AC grids, where power oscillations occur. Many solutions are proposed for ESS, for example, Flywheel Energy Storage (FESS) has been proposed at wind farm level, and it provides excellent support by releasing power into the networks during deep voltage sags. However, it is expensive, large and practical implementation is difficult [13]. Commonly, ESS is installed at converter level, particularly, at the DC link and during LVFRT operating akin to the dumping resistor. Systems employing batteries can maintain the DC voltages during faults and have good grid code compliance; nevertheless, its chemical storage elements present practical challenges during implementation [10]. Super-capacitor ESSs are seen as alternatives to avoid the aforementioned chemical storage issues; nonetheless, they suffer from self-discharge and dynamic performance, on large scale devices, which may make them unsuitable for LVFRT applications [10]. Superconducting Magnetic Energy Storage (SMES) [16] systems are being proposed to deal with high temperature issues, self-discharge and low efficiency, providing good performance during faults. However, the practical implementation, safety and cost of devices are limited by the state of existing technologies, but may be solvable in the long term.

Presented throughout this paper will be a detailed evaluation of three different LVFRT techniques at wind turbine level, and relative comparison with aid of MATLAB/Simulink simulations. A WECS employing a PMSG and grid-connected two-level VSC is modelled and subsequently used to perform quantitative comparisons between a number of LFRT techniques in order to establish the strengths and weaknesses of each method during balanced three-phase AC faults. The methods studied are:

- Dumping Resistor

- Super-Conductive Magnetic Energy Storage (SMES)

- Coordinated Converter Control
Each technique will be evaluated on its ability to alleviate stresses on the electrical and mechanical parts, reduce rise of DC link voltage and comply with grid codes.

\section{OVERVIEW OF WIND ENERGY CONVERSIONS SYSTEMS AND NETWORK FAULTS}

This section provides an overview of the issues that arise during network voltage sags at each stage of the conversion process of a two-level VSC with PMSG as per Fig. 1. Included for each stage are the principles and mathematical equations including the system model. These issues will be used to assess LVFRT techniques and minimise their effects.

\section{A. Wind Turbine}

When no LVFRT technique is applied during AC network faults, the loss of AC network power delivery imposes mechanical stresses, such as torque rejection and rotor overspeed in addition to overvoltage stress on the stator winding [7], [17]. The above problems are attributed to the inability to transfer active power into the AC network [7], [18], which subsequently is blocked at the generator converter or allowed to feed into the DC link. The turbine aerodynamic model utilised in the system simulations is based on (1) to (4). Where $P_{m}$ is the mechanical power output from the turbine, $C_{p}$ represents the turbine power coefficient, $\lambda$ is the tip speed ratio, $\beta$ is the pitch angle, $\rho$ is the air density, $A$ is the swept area of the turbine, $\mathrm{u}_{\mathrm{w}}$ is the wind speed, $\mathrm{R}$ is the blade radius, and $\Omega$ denotes the rotor speed. $C_{1}-C_{6}$ are turbine coefficients.

$$
\begin{gathered}
\mathrm{P}_{\mathrm{m}}=\mathrm{C}_{\mathrm{p}}(\lambda, \beta) \frac{\rho \mathrm{A}}{2} \mathrm{u}_{\mathrm{w}}{ }^{3} \\
\mathrm{C}_{\mathrm{p}}(\lambda, \beta)=\mathrm{C}_{1}\left(\frac{\mathrm{C}_{2}}{\lambda_{\mathrm{i}}}-\mathrm{C}_{3} \beta-\mathrm{C}_{4}\right) \mathrm{e}^{\left(-\frac{\mathrm{C}_{5}}{\lambda_{\mathrm{i}}}\right)}+\mathrm{C}_{6} \lambda_{\mathrm{i}} \\
\frac{1}{\lambda_{\mathrm{i}}}=\frac{1}{\lambda+0.08 \beta}-\frac{0.035}{\beta^{3}+1} \\
\lambda=\frac{\mathrm{R} \Omega}{\mathrm{u}_{\mathrm{w}}}
\end{gathered}
$$

The PMSG model is represented mathematically by (5) to (8), where the dq stator voltages and stator currents are represented by $\mathrm{V}_{\mathrm{ds}}, \mathrm{V}_{\mathrm{qs}}, \mathrm{I}_{\mathrm{ds}}$ and $\mathrm{I}_{\mathrm{qs}} . \mathrm{R}, \mathrm{L}_{\mathrm{d}}$ and $\mathrm{L}_{\mathrm{q}}$ represent the stator resistance and inductance of the $\mathrm{d}$ and $\mathrm{q}$ axis respectively. T represents torque, $\mathrm{p}$ represents pole pairs, $\omega$ is the rotor speed, $\mathrm{J}$ is the inertia, and $\mathrm{F}$ is viscous rotor friction coefficient.

$$
\begin{gathered}
\frac{\mathrm{d}}{\mathrm{dt}} \mathrm{i}_{\mathrm{ds}}=\frac{1}{\mathrm{~L}_{\mathrm{d}}} \mathrm{v}_{\mathrm{ds}}-\frac{\mathrm{R}}{\mathrm{L}_{\mathrm{d}}} \mathrm{i}_{\mathrm{ds}}+\frac{\mathrm{L}_{\mathrm{q}}}{\mathrm{L}_{\mathrm{d}}} \mathrm{p} \omega_{\mathrm{m}} \mathrm{i}_{\mathrm{qs}} \\
\frac{\mathrm{d}}{\mathrm{dt}} \mathrm{i}_{\mathrm{qs}}=\frac{1}{\mathrm{~L}_{\mathrm{q}}} \mathrm{v}_{\mathrm{qs}}-\frac{\mathrm{R}}{\mathrm{L}_{\mathrm{q}}} \mathrm{i}_{\mathrm{q}}-\frac{\mathrm{L}_{\mathrm{d}}}{\mathrm{L}_{\mathrm{q}}} \mathrm{p} \omega_{\mathrm{m}} \mathrm{i}_{\mathrm{ds}}-\frac{\psi \mathrm{p} \omega_{\mathrm{m}}}{\mathrm{L}_{\mathrm{q}}} \\
\mathrm{T}_{\mathrm{e}}=1.5 \mathrm{p}\left[\psi \mathrm{i}_{\mathrm{qs}}+\left(\mathrm{L}_{\mathrm{d}}-\mathrm{L}_{\mathrm{q}}\right) \mathrm{i}_{\mathrm{ds}} \mathrm{i}_{\mathrm{qs}}\right] \\
\frac{\mathrm{d}}{\mathrm{dt}} \omega_{\mathrm{m}}=\frac{1}{\mathrm{~J}}\left(\mathrm{~T}_{\mathrm{e}}-\mathrm{F} \omega_{\mathrm{m}}-\mathrm{T}_{\mathrm{m}}\right)
\end{gathered}
$$

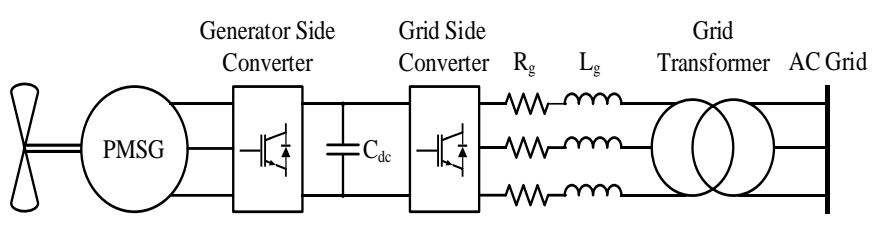

Fig. 1. Grid connected WECS employing PMSG and VSC. 


\section{B. Generator Side Converter}

In steady state, the generator side converter allows the generated active power with the aid of maximum point power tracking system to flow into the DC link and then to the AC collection network. The controller estimates the maximum torque extraction in the synchronous frame [22]. During an $\mathrm{AC}$ network fault, the generator side converter can be given a signal to block the power flow into the DC or allow it. The former will exacerbate the mechanical stress and the latter will require the excess energy to be dissipated or stored. The control scheme implemented in the system model facilitates Zero d-Axis Current (ZDC) due to its simplicity of implementation. Fig. 2. depicts the control scheme employed in the WECS model, and it is based on (9)-(11). The rotor speed reference $\omega_{\mathrm{r}} *$ is derived from a look-up table that uses representative wind speed from a typical wind power curve. The $\mathrm{V}_{\mathrm{dq}}$ values are calculated by the inner loop of the current controller of the converter. Gating signals are generated using Sinusoidal Pulse Width Modulation (SPWM).

$$
\begin{gathered}
\left\{\begin{array}{l}
\vec{i}_{s}=i_{d s}+i_{q s}=i_{q s} \\
i_{s}=\sqrt{i_{d s}{ }^{2}+i_{q s}{ }^{2}}=i_{q s} \text { for } i_{d s}=0
\end{array}\right. \\
T_{e}=1.5 p \psi_{\mathrm{r}} i_{s} \\
\mathrm{~V}_{\mathrm{s}}=\sqrt{\left(\mathrm{v}_{\mathrm{ds}}\right)^{2}+\left(\mathrm{v}_{\mathrm{qs}}\right)^{2}}=\sqrt{\left(\omega_{\mathrm{r}} \mathrm{L}_{\mathrm{q}} \mathrm{i}_{\mathrm{qs}}\right)^{2}+\left(\omega_{\mathrm{r}} \psi_{\mathrm{r}}\right)^{2}}
\end{gathered}
$$

\section{DC Link}

The DC link voltage is commonly regulated by the grid side converter, while the power is delivered into the $\mathrm{AC}$ network, and AC and DC side power balance is maintained [22]. The AC network faults create a mismatch between the power flowing into the DC link and delivered into the AC grid [22]. This mismatch causes large overvoltage in the DC link [7] due to excess or trapped energy. This causes extra stresses and potentially failure to the power switches in the power electronic converter or the capacitor if not managed [22]. The rate in which the overvoltage occurs is dependent on the size of the DC link capacitance. In [23], the authors have suggested the use of large or multiple capacitors as a means of slowing the overcharging process during $\mathrm{AC}$ faults. Nevertheless, such approach not only slows the overall dynamics of the system down, it increases the physical size and cost and is deemed to be an impractical solution [7].

\section{Generator Side Converter}

The most notable drawback to the grid side converter, operating in grid following mode, is the current controller.

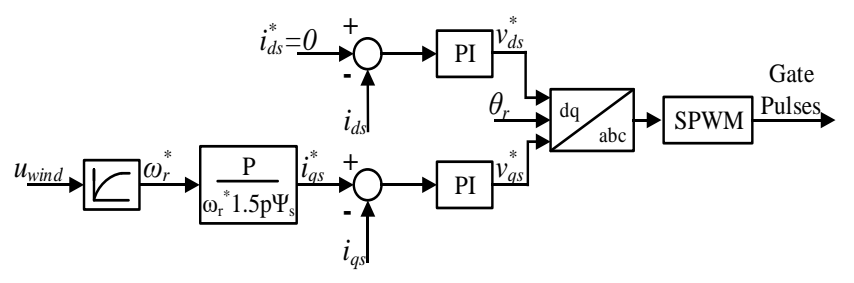

Fig. 2. Generator side converter control system.
The PI current controller typically operates in the synchronous (dq) reference frame, which tracks the network frequency required to synchronise via a Phase Locked Loop (PLL). A notable drawback of PI controllers is poor performance during AC network faults. There is a significant amount of research in the improvement of Grid side converter control in attempt to address the issue of non-linear operations. However, many of these techniques include an additional LVFRT technique which is beyond the scope of the works presented in this paper. Conventional Voltage Oriented Control (VOC) is used as per Fig. 3. which is derived from the grid side control scheme based on a decoupled Voltage Oriented control (VOC) scheme shown in Fig. 3. and derived from (12) [28]. The controller is equipped with an outer loop which regulates the DC link voltage $\left(\mathrm{V}_{\mathrm{dc}}\right)$ and defines reference current for the d-axis inner current controller, while the outer loop on $\mathrm{q}$-axis regulates reactive power $(\mathrm{Q})$ and defines the current reference for q-axis inner current controller. The Grid voltage reference is tracked, and the converter is synchronized by the reference angle $\left(\theta_{\mathrm{g}}\right)$ derived from a Phase Locked Loop (PLL) block also generating the voltage waveform reference to the SPWM.

$$
\left\{\begin{array}{l}
\frac{d i_{d g}}{d t}=\frac{\left(v_{d g}-v_{d i}+\omega_{g} L_{g} i_{q g}\right)}{L_{g}} \\
\frac{d i_{q g}}{d t}=\frac{\left(v_{q g}-v_{q i}-\omega_{g} L_{g} i_{d g}\right)}{L_{g}}
\end{array}\right.
$$

\section{LOW VOLTAGE FAULT RIDE THROUGH TECHNIQUES FOR VSC}

This section reviews the LVFRT techniques under investigation, which will be assessed and simulated in order to establish their merits and demerits. This section will also present the approach in which each technique is implemented into the system model.

\section{E. Dumping resistor}

The dumping resistor is connected in parallel with the DC link capacitor and is switched with a controllable semiconductor switch, which has low cost and control complexity, via hysteresis control or comparators [7], and is easily implemented and widely used commercially. The dumping resistor provides sufficient protection for the DC link capacitor and is commonly well coordinated with other LVFRT techniques. The significant drawbacks of the dumping resistor are the dissipation of heat and wasted energy during activation periods [9]. The IGBT used to switch in the dumping resistor, is done so by use of a hysteresis controller. The hysteresis has been set in a manner

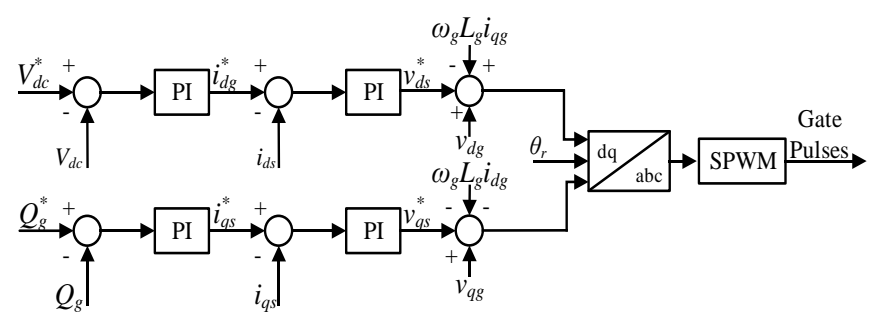

Fig. 3. Grid side converter control system. 
so that it will not activate during normal operation. The set points for the controller are $R_{\text {on }}$ and $R_{\text {off }}$ are set to operate at 1.1 and $1.05 \mathrm{pu}$ of $\mathrm{V}_{\mathrm{dc}}$ respectively

\section{F. Superconducting Magnetic Energy Storage (SMES)}

Generally, ESSs are cited as a means to enhance LVFRT and smooth power output of the WECS to avoid the dissipation of unutilised energy in a dumping resistor during $\mathrm{AC}$ faults. Superconductive material for energy storage is highly efficient, fast-responding and has high power density [10]. During AC network faults, the excess energy in the DC is stored in the SMES and can be utilised for power smoothing applications. SMES can provide superior response and simulation results [8], [25] and shows enhanced LVRT performance when used at turbine level. Like equivalent storage devices, there is little in literature to support the management of charging to ensure efficient use during LVFRT periods. Current drawbacks to SMES systems are the high capital costs and requirement of cryogenic cooling, which incurs additional losses and specialist maintenance requirements [25]. The SMES system is modelled based on the circuit as shown in Fig. 4. which facilitates three modes of operation, stated in Table I, with SMES dimensioned as per [26]. The modes of operation are defined by fixed setpoints, where 1.1pu of $\mathrm{V}_{\mathrm{dc}}$ initiates charging, 0.9pu of $\mathrm{V}_{\mathrm{dc}}$ initiates discharging and operating in standby mode within these limits. This method neglects power smoothing functionality and assesses LVFRT performance only.

\section{G. Coordinated Converter Control}

As a means to mitigate requirements for additional hardware, thus reducing converter size and weight, [15], [27], [28] propose methods of coordinating grid side and generator converters during AC network faults to maintain the DC link operating limits. The control systems in [15], [27] are configured in a manner that the terminal voltage $(\mathrm{pu})$ on the on the network proportionally affects the power input from the PMSG to the DC link. [20] suggests this method can be utilised without additional DC link equipment, however, the results do not state the impacts on the mechanical system. In [19], it is suggested that a dumping resistor is still required, minimising the attactiveness of the option.

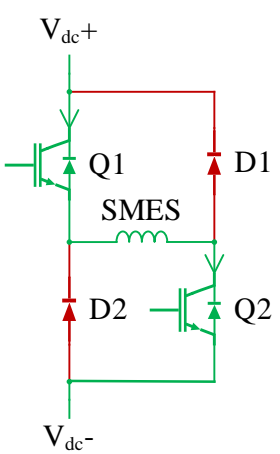

a) Charge

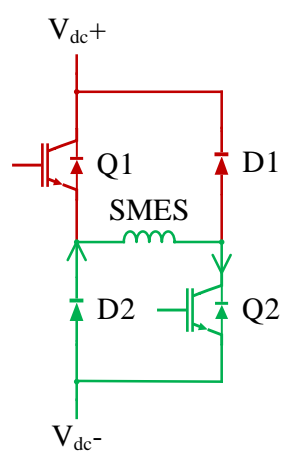

b) Stand-by

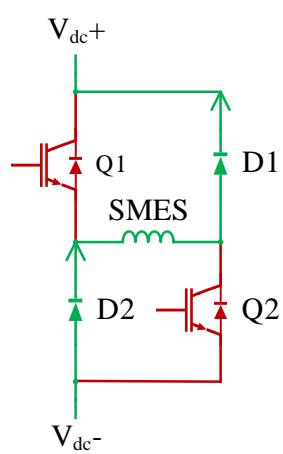

c) Discharge
TABLE I SMES OPERATION AND SWITCHING TABLE

\begin{tabular}{|l|c|c|c|c|}
\hline \multicolumn{1}{|c|}{ Mode } & $\mathbf{Q}_{\mathbf{1}}$ & $\mathbf{Q}_{\mathbf{2}}$ & $\mathbf{D}_{\mathbf{1}}$ & $\mathbf{D}_{\mathbf{2}}$ \\
\hline Charge & 1 & 1 & 0 & 0 \\
\hline \multirow{2}{*}{ Stand-by } & 0 & 1 & 0 & 1 \\
\cline { 2 - 5 } & 1 & 0 & 1 & 0 \\
\hline Discharge & 0 & 0 & 1 & 1 \\
\hline
\end{tabular}

IV. SIMULATION RESULTS

This section details the WECS system, network and AC network fault parameters used, and results of simulations for each LVFRT technique evaluated. System modelling has been based on the parameters in Table II, which defines MV collector network, line parameters [29], PMSG [28], the twolevel VSC, including grid side converter filters, and of the applied AC network faults, used to assess the LVFRT techniques.

\section{TABLE II SYSTEM PARAMETERS}

\begin{tabular}{|c|c|c|}
\hline Description & Value & Units \\
\hline Grid Voltage (ph-ph) & 25 & $\mathrm{kV}$ \\
\hline Grid Frequency & 50 & $\mathrm{~Hz}$ \\
\hline Grid Base Apparent Power & 100 & MVA \\
\hline Grid Short Circuit (R/X) Ratio & 7 & - \\
\hline Line Resistances $\left(\mathrm{R}_{1}, \mathrm{R}_{0}\right)$ & $0.013,0.386$ & $\Omega / \mathrm{km}$ \\
\hline Line Inductances $\left(\mathrm{L}_{1}, \mathrm{~L}_{0}\right)$ & $0.934,4.126$ & $\mathrm{mH} / \mathrm{km}$ \\
\hline Line Capacantences $\left(\mathrm{C}_{1}, \mathrm{C}_{0}\right)$ & $12.74,7.75$ & $\mathrm{nF} / \mathrm{km}$ \\
\hline Line Length & 50 & $\mathrm{~km}$ \\
\hline Transformer Primary Volage (ph-ph) & 690 & $\mathrm{~V}$ \\
\hline Transformer Secondary Volage (ph-ph) & 25 & $\mathrm{kV}$ \\
\hline Transformer Power Rating & 5 & MVA \\
\hline Transformer Vector Group & Yd1 & - \\
\hline PMSG Mechanical Power $\left(\mathrm{P}_{\mathrm{m}}\right)$ & 2 & MW \\
\hline PMSG Torque $\left(\mathrm{T}_{\mathrm{m}}\right)$ & 852.77 & $\mathrm{kNm}$ \\
\hline PMSG Rotor Speed $\left(\omega_{\mathrm{r}}\right)$ & 2.31 & $\mathrm{rad} / \mathrm{s}$ \\
\hline PMSG Stator Resistence $\left(\mathrm{R}_{\mathrm{s}}\right)$ & 0.73 & $\mathrm{~m} \Omega$ \\
\hline PMSG d-axis Synchronous Inductance $\left(\mathrm{L}_{\mathrm{d}}\right)$ & 1.21 & $\mathrm{mH}$ \\
\hline PMSG q-axis Synchronous Inductance $\left(\mathrm{L}_{\mathrm{q}}\right)$ & 2.31 & $\mathrm{mH}$ \\
\hline PMSG Rotor Flux $(\psi)$ & 4.696 & $\mathrm{~Wb}$ \\
\hline PMSG Pole Pairs (p) & 30 & - \\
\hline PMSG Turbine Ineria $(\mathrm{J})$ & 1200 & $\mathrm{Kgm}^{2}$ \\
\hline DC Link Voltage $\left(\mathrm{V}_{\mathrm{dc}}\right)$ & 1250 & Vdc \\
\hline DC Link Capacitor (C) & 82 & $\mu \mathrm{F}$ \\
\hline Grid Side Filter Resistance $\left(\mathrm{R}_{\mathrm{g}}\right)$ & 2.4 & $\mathrm{~m} \Omega$ \\
\hline Grid Side Filter Inductance $\left(\mathrm{L}_{\mathrm{g}}\right)$ & 5 & $\mu \mathrm{H}$ \\
\hline IGBT Internal Resistance $\left(\mathrm{R}_{\mathrm{on}}\right)$ & 1 & $\mathrm{~m} \Omega$ \\
\hline Balanced Fault Resistence (3Ph-E) & 10 & $\mathrm{~m} \Omega$ \\
\hline Time Fault Applied & 1 & $\mathrm{~s}$ \\
\hline Fault Duration & 140 & $\mathrm{mS}$ \\
\hline
\end{tabular}

Fig. 4. Superconducting magnetic energy storage system, modes of operation. 


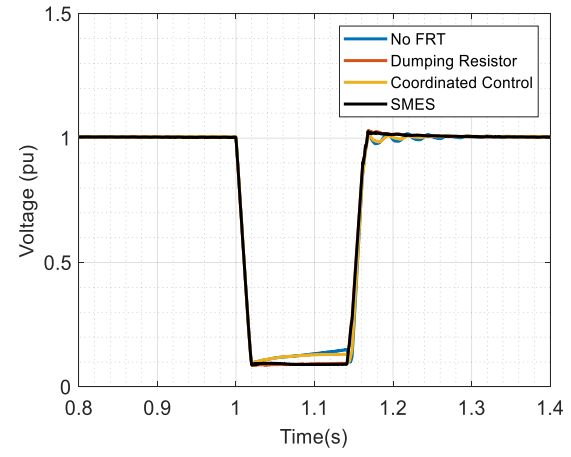

a) PCC Voltage

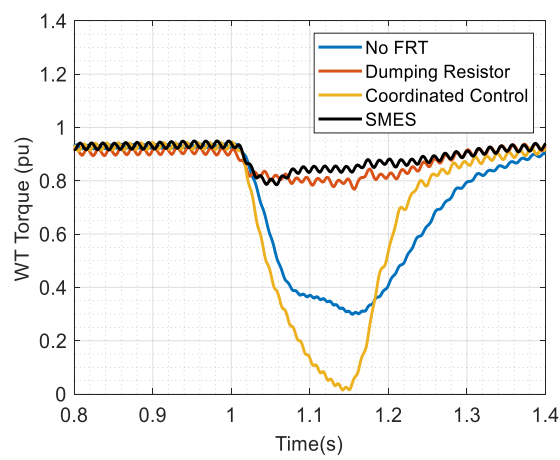

d) Wind Turbine Torque

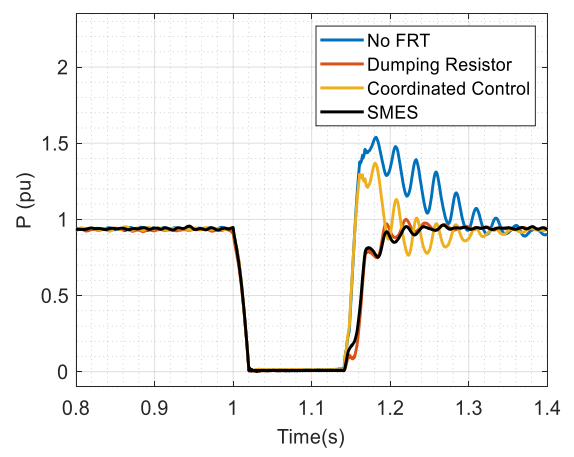

b) PCCReal Power

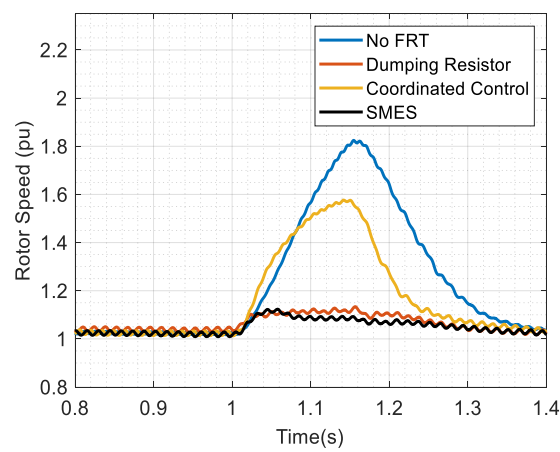

e) Wind Turbine Rotor Speed

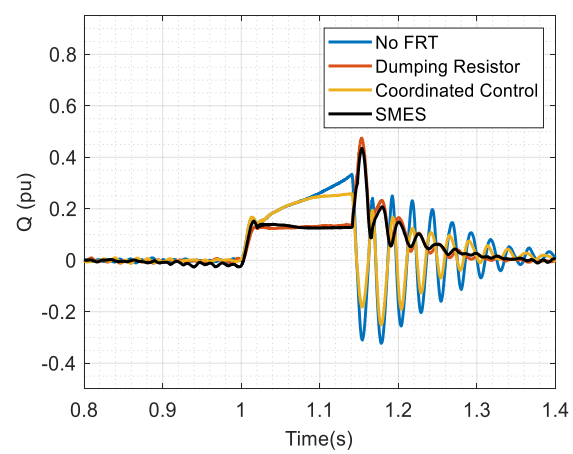

c) PCC Reactive Power

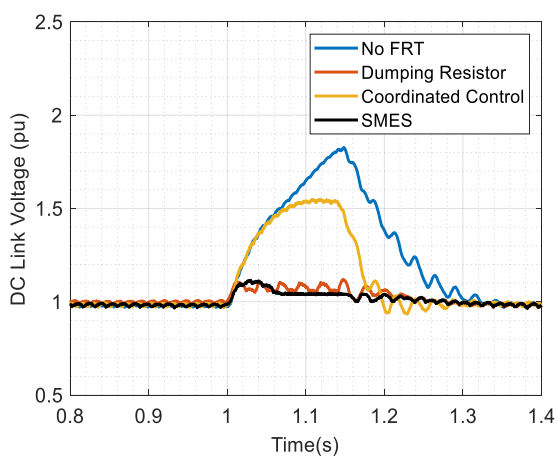

f) DC Link Voltage

Fig. 5. Network, Turbine and converter measurements during a three-phase and earth fault of a duration of $140 \mathrm{~ms}$

Fig. 5. shows the simulation results for the three-phase to ground balanced fault at the Point of Common Coupling (PCC), WECS and VSC. Observe that when no LVFRT techniques are implemented and, to a lesser extent, coordinated control technique, power oscillations occur and high mechanical stresses are observed on the generator over short timescales. The applied AC network fault results in a network voltage of approximately $0.1 \mathrm{pu}$, shown in Fig. 5a. Real power in Fig. 5b. shows that techniques that dissipate the trapped energy (dumping resistor and SMES) restore power to the network with little overshoot compared to No LVFRT technique and coordinated control. Fig. 5c. shows that when the DC link voltage is allowed to exceed the pre-specified limits during $\mathrm{AC}$ fault, the reactive power output from the grid side converter becomes uncontrolled and oscillatory during restoration. Fig. 5d. shows that the use of a coordinated control puts high stress on the mechanical system through rapid de-loading, in contrast to low mechanical stresses using methods which dissipate the excess DC link energy. Fig. 5e. reiterates the stresses put on the mechanical system, with no LVFRT technique showing the largest rotor over-speed, while the DC link dissipation methods exhibit relatively constant speeds, with only small acceleration. Fig. 5f. shows the effects of LVFRT techniques on the electrical stresses imposed to the DC link. Without LVFRT technique, the DC link exhibits excessive over-voltage, which breaches limits. In contrast, techniques such as the dumping resistor and SMES appear to maintain control over the DC link voltage. The coordinated control technique reduces the DC voltage rise marginally but transfers the stress from the converter to the PMSG.

\section{DISCUSSION}

Table VI details an evaluation of the techniques based on the results of the simulations and addresses each of the techniques' abilities to dissipate the trapped energy from the DC link during AC fault and the effects to the other connected components.

TABLE III EVALUATION OF LVFRT TECHNIQUES

\begin{tabular}{|l|c|c|c|}
\hline \multicolumn{1}{|c|}{ Description } & $\begin{array}{c}\text { Dumping } \\
\text { Resistor }\end{array}$ & SMES & $\begin{array}{c}\text { Coordinated } \\
\text { Control }\end{array}$ \\
\hline $\begin{array}{l}\text { Grid Code } \\
\text { Compliance }\end{array}$ & High & High & Moderate \\
\hline Efficiency & Low & High & High \\
\hline Control Complexity & Low & Moderate & Low \\
\hline Mechanical Stress & Low & Low & High \\
\hline Electrical Stress & Low & Low & Moderate \\
\hline $\begin{array}{l}\text { Hardware } \\
\text { Complexity }\end{array}$ & Moderate & Moderate & Low \\
\hline $\begin{array}{l}\text { Practical } \\
\text { Implementation }\end{array}$ & Low & Moderate & Low \\
\hline System Cost & Low & High & Low \\
\hline
\end{tabular}

As discussed, the key challenges to LVFRT have been stated as maintaining the DC link within limits and reactive power delivery to the network. It is clear that present techniques can deliver this, but sometimes at the expense of imposing stresses at other points of the systems. It can be stated that in order to allow for efficient and effective performance during LVFRT, the excess energy during an AC fault must be dissipated or stored externally to the WECS. The use of a coordinated converter technique shows that DC link voltage limits are breached, causing stress to the electrical systems in addition to mechanical equipment. From Table VI, the dumping resistor performs well. However, with AC network inertia and fault levels reducing, operation in weak electrical 
grids may result in overheating and mis-operation of dumping resistors during voltage fluctuations in post-fault recovery. SMES stores the trapped energy and has the potential to recover the power output of the converter during fault, which is a key attribute for future power networks. Although SMES has potential, there are existing challenges for the implementation of it at wind farm and turbine level. In addition to the practical challenges, the capital cost is high and the benefits it provides need to be estimated against cost and frequency of faults, to which little literature exists. In addition to this, the charge and energy to effectively enhance LVFRT would require management.

\section{CONCLUSIONS}

This paper presented a comparison of LVFRT techniques for WECS, which are essential for grid code compliance. The base-case (no LVFRT technique), dumping resistor, SMES and coordinated converter control approach were all appraised based on works published in literature and simulations. The results of the evaluation and simulations show that there is a requirement for external devices in WECS to dissipate trapped DC link energy during an AC network fault. Techniques which look to remove external devices from the system transfer the stresses to the mechanical parts and converter DC link. The dumping resistor is fully compliant with grid codes and relieves the system from both mechanical and electrical stresses and allows the full system to ride through. In a weakening electrical grid, where power and voltage oscillations become more likely, this may limit its use in future networks as the device may suffer mis-operation and overheat in the recovery periods. SMES presents a good solution to allow systems to comply with LVFRT requirement, minimise stress and operate in weak electrical grids, with good attributes over other ESS technologies presently proposed. The main limitations on the system is its high capital costs, practical implantation requirements and charge management.

\section{REFERENCES}

WWEA, "Global Wind Installation," Wind Energy International, 2018 .

[2] National Grid ESO, "System Operability Framework: Impact of declining short circuit level," 2018.

[3] M. Tsili and S. Papathanassiou, "A review of grid code technical requirements for wind farms," IET Renew. Power Gener., vol. 3, no. 3, pp. 308-332, 2009.

[4] C. Sourkounis and P. Tourou, "Grid Code Requirements for Wind Power Integration in Europe," Conf. Pap. Energy, vol. 2013, pp. $1-9,2013$.

[5] I. Erlich and U. Bachmann, "Grid code requirements concerning connection and operation Of wind turbines in Germany," 2005 IEEE Power Eng. Soc. Gen. Meet., vol. 2, pp. 1253-1257, 2005.

[6] F. Kalverkamp, B. Schowe-Von Der Brelie, T. D. Nguyen, T. Mertens, and M. Meuser, "Comparative analysis of European Grid Codes and compliance standards for distributed power generation plants with respect to future requirements of ENTSO-E and CENELEC," Int. ETG Congr. 2015; Die Energiewende Blueprints New Energy Age, pp. 605-610, 2015.

[7] J. F. C. and R. Watson, "Low-voltage ride-through of a full converter wind turbine with permanent magnet generator," IET Renew. Power Gener., vol. 3, no. 1, pp. 182-189, 2007.

[8] J. Liu, H. Zhang, B. Yang, and Y. Min, "Fault ride through under unbalanced voltage sag of Wind Energy Conversion System using Superconducting Magnetic Energy Storage," 2015 IEEE 2nd Int. Futur. Energy Electron. Conf. IFEEC 2015, pp. 1-6, 2015.
[10]

of Wind Power Generators," in Energy Procedia, 2017.

Rania Assem Elsayed Ibrahim, "Low Voltage Ride-Through of Permanent Magnet Synchronous Generator Wind Energy Systems," 2014.

[11] H. Bindner, Power Control for Wind Turbines in Weak Grids: Concepts Development, vol. 1118, no. March. 1999.

[12] A. Gencer, "Analysis and control of fault ride-through capability improvement for wind turbine based on a permanent magnet synchronous generator using an interval type-2 fuzzy logic system," Energies, vol. 12, no. 12, 2019.

[13] R. A. Ibrahim, M. S. Hamad, Y. G. Dessouky, and B. W. Williams, "A review on recent low voltage ride-through solutions for PMSG wind turbine," SPEEDAM 2012 - 21st Int. Symp. Power Electron. Electr. Drives, Autom. Motion, pp. 265-270, 2012.

[14] X.-Y. Xiao, R.-H. Yang, X.-Y. Chen, Z.-X. Zheng, and C.-S. Li, "Enhancing fault ride-through capability of DFIG with modified SMES-FCL and RSC control," IET Gener. Transm. Distrib., vol. 12, no. 1, pp. 258-266, 2018.

[15] P. Dey, M. Datta, and N. Fernando, "A coordinated control of grid connected PMSG based wind energy conversion system under grid faults," 2017 IEEE 3rd Int. Futur. Energy Electron. Conf. ECCE Asia, IFEEC - ECCE Asia 2017, no. 2, pp. 597-602, 2017.

[16] Seung-Tak Kim, Byung-Kwan Kang, Sun-Ho Bae, and JungWook Park, "Application of SMES and Grid Code Compliance to Wind/Photovoltaic Generation System," IEEE Trans. Appl. Supercond., vol. 23, no. 3, p. 5000804, 2012.

[17] A. K. Thet and H. Saitoh, "Pitch control for improving the lowvoltage ride-through of wind farm," Transm. Distrib. Conf. Expo. Asia Pacific, T D Asia 2009, pp. 1-4, 2009.

[18] S. Yang, T. Zhou, L. Chang, Z. Xie, and X. Zhang, "Analytical Method for DFIG Transients during Voltage Dips," IEEE Trans. Power Electron., vol. 32, no. 9, pp. 6863-6881, 2017.

[19] T. Ackermann, Wind Power in Power Systems. 2005.

[20] M. H. Hansen, A. Hansen, T. J. Larsen, S. Øye, P. Sørensen, and P. Fuglsang, Control design for a pitch-regulated, vari-able speed wind turbine, vol. 1500, no. January. 2005.

[21] M. Abbes and J. Belhadj, "Supervisory control strategy for optimal integration of direct drive wind turbine to the grid," 2013 Int. Conf. Electr. Eng. Softw. Appl. ICEESA 2013, no. 4, pp. 1-7, 2013.

[22] B. Wu, Y. Lang, N. Zargari, and S. Kouro, "Variable-Speed Wind Energy Systems with Synchronous Generators," Power Convers. Control Wind Energy Syst., pp. 275-316, 2011.

[23] Huchel, M. S. El Moursi, and H. H. Zeineldin, "A Parallel Capacitor Control Strategy for Enhanced FRT Capability of DFIG," IEEE Trans. Sustain. Energy, vol. 6, no. 2, pp. 303-312, 2015.

[24] B. Wu, Y. Lang, N. Zargari, and S. Kouro, "Power Converters in Wind Energy Conversion Systems," Power Convers. Control Wind Energy Syst., pp. 87-152, 2011.

[25] C. Huang, X. Y. Xiao, Z. Zheng, and Y. Wang, "Cooperative Control of SFCL and SMES for Protecting PMSG-Based WTGs under Grid Faults," IEEE Trans. Appl. Supercond., vol. 29, no. 2, pp. 1-6, 2019.

[26] M. G. Taul, X. Wang, P. Davari, and F. Blaabjerg, "Robust Fault Ride-Through of Converter-based Generation during Severe Faults with Phase Jumps," IEEE Trans. Ind. Appl., vol. PP, no. c, p. 1, 2019.

[27] G. P. Adam, K. H. Ahmed, S. J. Finney, and B. W. Williams, “AC fault ride-through capability of a VSC-HVDC transmission systems," 2010 IEEE Energy Convers. Congr. Expo. ECCE 2010 - Proc., pp. 3739-3745, 2010.

[28] P. T. H. Nguyen, S. Stüdli, J. H. Braslavsky, and R. H. Middleton, "Coordinated Control for Low Voltage Ride Through in PMSG Wind Turbines," IFAC-PapersOnLine, vol. 51, no. 28, pp. 672677, 2018.

[29] Y. Xia, "Current Source Based DC Transmission System for Multiple Wind Turbine Interfacing," Thesis, no. October, 2011. 